\title{
Black-Bridge data in the detection of forest area changes in the example of Sudety and Beskidy
}

\author{
Tomasz Hycza 凶, Krzysztof Stereńczak, Radomir Bałazy
}

Forest Research Institute, Department of Forest Resources Management, Sękocin Stary, Braci Leśnej 3, 05-090 Raszyn, Poland, phone: +48 22 7150343, e-mail: t.hycza@ibles.waw.pl

\section{Abstract}

Two change detection techniques (NDVI differencing and post-classification analysis) were compared, in order to detect canopy cover changes in forests on the area of twelve forest districts in the Sudety and West Beskidy Mountains in Poland, using 2012 and 2013 Black-Bridge satellite images. Although the classification accuracy of the respective images was high (about 95\%), the accuracy of the difference in bi-temporal images was much worse because of the short time between the dates of images and the imperfection of the algorithm calculating the unclear boundary between the forest and no-forest areas. NDVI differencing method and thresholding brought much better overall results, although roads, clouds and fogs caused much problem performing pseudo-changes.

\section{KEY WORDS}

remote sensing, Black-Bridge, change detection, NDVI, post-classification analysis

\section{INTRODUCTION}

Vegetation cover change plays an important role in the monitoring processes that take place in the environment. Change detection enables the effects of human activity, climate change and amount of biomass. The main source of information of changes is the satellite remote sensing. Satellite remote sensing provides the means to compare unified data from all over the world in a relatively short time. The goal of this paper is to present the possibility of using medium resolution Black-Bridge satellite images to detect changes occurring in the State Forests in Poland. The data were collected as a part of the project realized in the Forest Research Institute entitled "The creation of the forest informatics system for monitoring and forest shape assessment for Sudety and West Beskidy Mountains 2012-2017” (http://www. monitoringgor.pl/) funded by The State Forests.

Vegetation cover detection has been studied in several literatures. During the last 100 years, the area of forest has been stable or even slowly increasing. The elimination of agriculture on slopes and slick soils slowed down the erosion, while the enlarging areas of pastures and abandoned lands have had positive effects on the environmental conditions. The growing density of urban lands and the abandonment of agricultural activities resulted in the extinction of cultural landscapes and plant habitats connected with them. Poor Norway spruce monocultures are now growing on the old pastures and meadows there (Potocki 2000; Szymura et al.2010).

Changes have occurred in the West Sudety Mountains; these changes will probably continue but not as 
fast as it occurred in the past. Although the area of forest lands in slowly increasing, it is still possible to observe the effects of the past deforestations caused by the glass and textile industry (heating furnaces with wood and potash production). The glass and textile industry caused a massive decrease in the rich mixed forests, which were replaced by the poor spruce monocultures (Bałazy 2002).

The increasing area of forests was also spotted on the maps and satellite images of the West Karpaty near Orawa. The forest area increased from $25 \%$ in 1823 to $40 \%$ in the $21^{\text {st }}$ century. The secondary succession occurred on the abandoned crop lands and pastures placed 800 meters above sea level in the subalpine spruce forests zone. Changes in the environment are directly caused by the changes in the human activity (abandoning agriculture and switching to forestry and tourism) and are connected with a noticeable change in the local employment structure.

In order to analyze large area changes and global trends, it is important to take a look at the influence of human activity on forest management. Since the Forest Digital Map is available, there is a need to update it every following year (Stereńczak 2006a, 2006b). GPS and GIS technologies used in the process, but the usage of remote sensing data makes it faster, cheaper and more accurate. It also enables the detection of changes on non-easily accessible areas (Stereńczak 2006a; Wężyk and Ciechanowski 2005).

There are many methods of change detection by using the remote sensing data. Some of the methods are mentioned below:

- Band differencing (using values in the image bands or vegetation indexes)

- Combined image classification and post-classification analysis

- Principal Component Analysis and Tasseled Cap transformations

- Visual analysis, GIS techniques and models

Band differencing method deals with substracting or dividing values in separate bands or vegetation indexes calculated using image bands (such as NDVI) (Mas 1999). Pixels representing areas of changes are on the sides of the histogram. It is crucial to set the correct thresholds for map accuracy (Mas 1999).

The combined classification of the two images requires a combination of bands from the two separate images and classifies them as one multispectral image. The areas of changes should be represented by different spectral characteristics than the areas where no changes were observed ( $\mathrm{Lu}$ et al. 2004).

The post-classification analysis requires that the two images classified separately intersect the result maps to display the areas of changes. These methods were compared by Bochenek (Bochenek 2004), Lewiński and Niedzielko (Lewiński and Niedzielko 2012) and Mas (Mas 1999). Each time, the post-classification analysis turned out to be the most effective method.

Classification may be fully automatic (performed using only few parameters such as the number of classes, defined by the user) or semi-automatic - performed using test polygons, which the user is required to draw on his own (Campbell and Wynne 2009; Lillesand et al. 2007). Classification may be pixel-based (when each pixel is classified separately) or object-based - when groups (clusters) of pixels are segmented and then classified (Lewiński 2007)

An example of a pixel-based approach evaluated the ability of the red edge band of Black-Bridge imagery to discriminate different levels of insect defoliation in an African savanna by comparing the results obtained from the two classifiers: Random Forest and Support Vector Machine. They were applied using different sets of spectral analysis involving the red edge band: all bands versus 4 bands (excluding red-edge), NDVI versus NDVI-RE and all bands + NDVI versus All bands + NDVI-RE. The highest accuracy was achieved for the NDVI-RE composition classified with the Random Forest and SVM algorithms ( $84 \%$ and 83\%) (Adelabua et al. 2014). That's an example of a pixel-based approach.

The object-based classification method was performed to investigate forest losses in the Bavarian Forest National Park between April and October 2011. In the monotemporal classification, each dataset from a single vegetation period was segmented and classified into "Forest" and "Non-forest" using the mean of the Blue band, the Blue/Green ratio index, the Brightness and the Normalized Difference Vegetation Index. The change detection process was also executed between each corresponding Black-Bridge band. After performing band differencing and segmentation, the images were classified into "changes" and "no changes". The next step was to classify "changes" into "forest losses" and "other changes" (such as clouds). Finally, the "forest 
losses" were classified into "coniferous" and "deciduous". Classification was performed using criteria based on the values of indices such as Blue/Green ratio, NDVI and Brightness. The study revealed that using the raw bands without pre-processing steps outperformed using the Normalization and Standardization. The authors reached an overall accuracy of $96.7 \%$ (0.86 - Kappa) (Elatawneh et al. 2012); (Elatawneh et al. 2014).

The object-based classification method was also performed to classify areas within 5 test zones in Bulgaria to one of the three categories: Good Agricultural Condition Land, Potential Non-Good Agricultural Land and Non-Good Agricultural Land. 7 Black-Bridge images from April to September 2009 was used. A 5-band image containing the stacked NDRE (NDVI with the red band replaced by the Red Edge band) images for the months of April, May, June, July and September was created in ERDAS Imagine. It was finally rescaled to the dynamic range of the Black-Bridge imagery, which is 12-bit. The 5-band stacked NDRE image was segmented and classified using different variables, such as brightness, mean value of red, relative border to, border index and thematic attribute. The overall thematic accuracy of the land cover classification was about $81 \%$ (Tapsall et al. 2010).

Another change detection method based on classification is the decision tree that was used to validate the accuracy of Landsat data in Brazil between September 2010 and May 2013 using the Black-Bridge images. A 500 -sample block $\left(24500 \mathrm{~km}^{2}\right)$ was created at various locations in Brazil, while only nine were used for further analysis. Mapping and change detection was implemented using a classification tree algorithm based on user applied training data resulting in a change/nochange map. The overall accuracy between Landsat and Black-Bridge forest cover loss maps was about 96.2\% $(61.7 \%$ - the user's accuracy, $55.6 \%$ - the producer's accuracy). According to the Black-Bridge data, the loss of forest cover was about 2800 square kilometers, while according to Landsat data, it was less than 1650. It shows that there was more forest cover change detected through the Black-Bridge data than the Landsat data (Rodriguez et al. 2014).

To detect forest changes on Black-Bridge images, Tasseled Cap transformation may be useful. It was to detect forest disturbances in British Columbia between July and September 2012. The Vegetation Resources Inventory disturbance polygons were used to select seven overlaying bitemporal Black-Bridge image pairs which contained several disturbance events occurring between acquisition times. A set of 50 Black-Bridge images (with extracted no-forest areas) from across the Province were transformed using the Principal Component Analysis, which formed the basis for the tasseled cap coefficients. The disturbance index was used to substract the standardized greenness and wetness values from the standardized scene brightness. Finally, the subtraction was used to create univariate difference images where negative values indicated increased vegetation, while positive values indicated vegetation loss. The overall accuracy across the landscape was high, ranging between $89 \%$ and $96 \%$ (Arnett 2014).

The use of remote sensing tools and data to detect changes in the Polish forest areas are still very poor. Many surveys were carried out to detect landscape changes, not in the forests but among forests, agricultural and urban lands.

The aim of the study is to identify forest changes in the twelve forest districts in Sudety and West Beskidy Mountains in Poland using medium resolution BlackBridge satellite images, testing the two change detection methods: post-classification analysis and NDVI differencing. Besides the accuracy of these methods, the influence of environmental features on the process of potential Forest Digital Map update was investigated.

\section{Material AND Methods}

The area "A" consists of 2 forest districts in the southwestern part of Dolnośląskie voivodeship: Świeradów and Szklarska Poręba $\left(292.4 \mathrm{~km}^{2}\right)$. The most common tree species are: spruce $(72 \%)$, pine $(10 \%)$, birch $(9 \%)$, oak (5\%) and beech (3\%). $12 \%$ of the forest area belongs to I age class, $27 \%$ - II, $20 \%$ - III, $12 \%$ - IV, $10 \%-\mathrm{V}$, $3 \%-$ VI and $2 \%-$ VII. $1 \%$ are the no-forest areas and $13 \%$ belong to the areas subjected to regeneration (Forest Data Bank 2014).

The area " $\mathrm{B}$ " consists of 4 forest districts in the southern part of Dolnośląskie voivodeship: Zdroje, Bystrzyca Kłodzka, Lądek Zdrój and Międzylesie $\left(495.5 \mathrm{~km}^{2}\right)$. The most common tree species are: spruce $(83 \%)$, beech $(8 \%)$, pine $(4 \%)$, oak $(2 \%)$ and birch $(1 \%)$. $6 \%$ of the forest area belongs to I age class, $11 \%-$ II, $19 \%-\mathrm{III}, 12 \%-\mathrm{IV}, 14 \%-\mathrm{V}, 10 \%-\mathrm{VI}$ and $5 \%-$ VII. 
$23 \%$ belongs to the areas subjected to regeneration (Forest Data Bank 2014).

The area "C" consists of 6 forest districts in the southern part of Śląskie voivodeship: Węgierska Górka, Wisła, Ujsoły and partly - Ustroń, Jeleśnia and Bielsko $\left(489.5 \mathrm{~km}^{2}\right)$. The most common tree species are: spruce $(62 \%)$, beech $(23 \%)$, pine $(5 \%)$, fir $(4 \%)$, oak $(3 \%)$ and birch (2\%). $14 \%$ of the forest area belongs to I age class, $16 \%$ - II, $12 \%$ - III, $13 \%$ - IV, 9\% - V, 5\% - VI and 3\% - VII. $26 \%$ belongs to the areas subjected to regeneration (Forest Data Bank 2014) (Fig. 1).

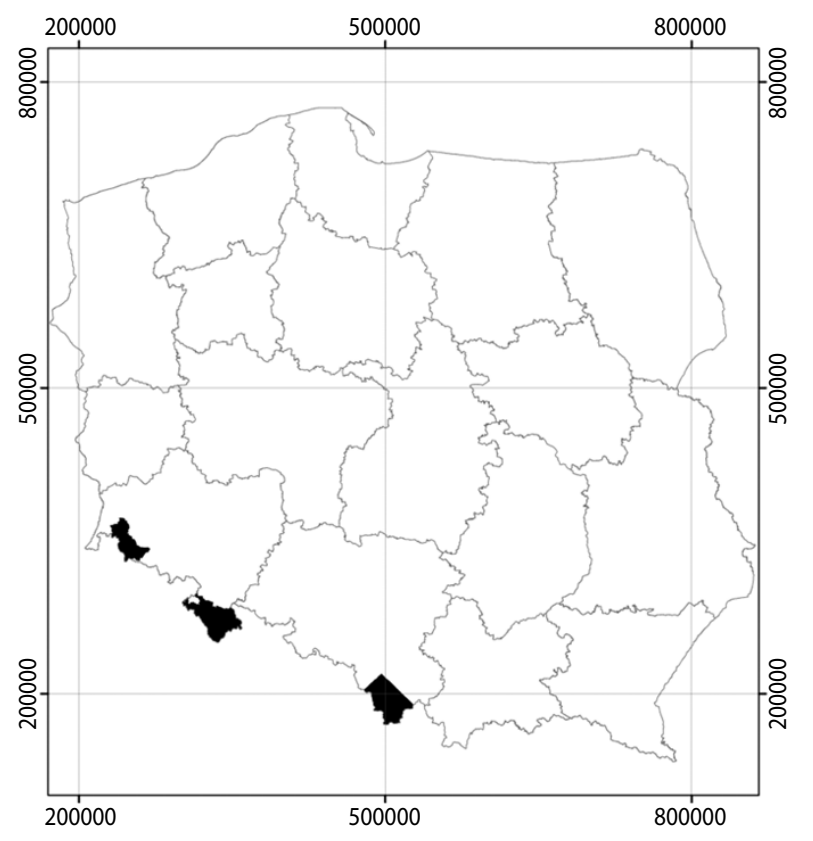

Figure 1. The areas of investigation
Six satellite images were used to analyze the forest vegetation cover changes. The spatial, radiometric and spectral resolution is shown in Table 1. The images were modified by the atmospheric correction and orthorectification using Digital Elevation Model. The noises and distortion errors were eliminated. If the area was visualized on more than one image, the images were mosaicked into one. The RMSE was not greater than 1.5 pixels ( 3 in the particularly hard conditions).

Table 1. The Black-Bridge satellite imagery parameters

\begin{tabular}{|l|c|}
\hline Spatial resolution & $6.5 \mathrm{~m}$ (5 m after the resampling) \\
\hline Radiometric resolution & $\begin{array}{r}\text { 12-bit (16 after the atmospheric } \\
\text { correction })\end{array}$ \\
\hline Blue band & $(440-510 \mathrm{~nm})$ \\
\hline Green band & $(520-590 \mathrm{~nm})$ \\
\hline Red band & $(630-685 \mathrm{~nm})$ \\
\hline Red Edge band & $(690-730 \mathrm{~nm})$ \\
\hline Near Infra-Red band & $(760-850 \mathrm{~nm})$ \\
\hline
\end{tabular}

The images for area "A" were taken 02.08.2012 and 21.07.2013, for area "B" - 02.09.2012 and 16.08.2013, while for area "C" 24.07.2012 and 24.07.2013.

The satellite images were already georectified. Unfortunately, they didn't fit very well with each other. The differences were clearly visible on the borders of the investigated areas and in the trajectory of forest roads and paths. The change detection map based on these images would include polygons illustrating these errors, besides the changes that really happened between the terms of the images. The reason why the images didn't
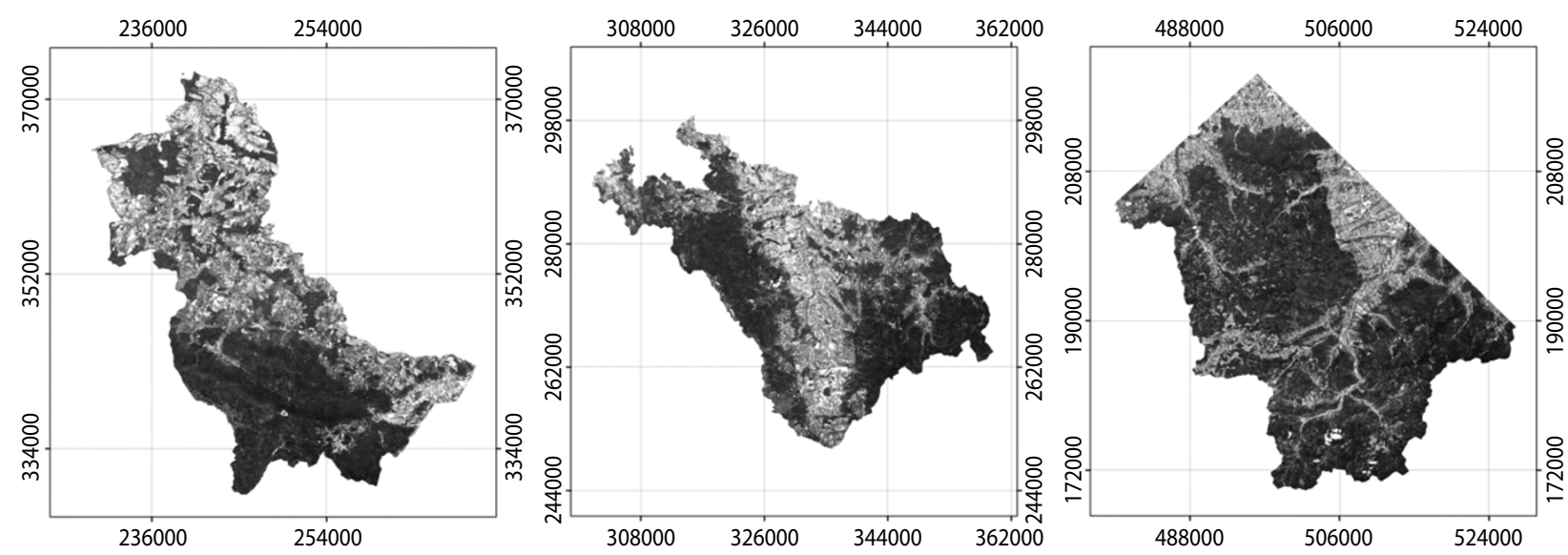

Figure 2. The areas of investigation 
fit was that they were taken by the satellite moving on the adjacent orbits, and not the same orbits. The errors could also be a result of the height difference of the investigated areas. To avoid these errors, 300 control points were set on the images and used to rectify them once more using the Bilinear method (recommended for continuous data). The RMSE was always less than 2.5 pixel. Finally, the no-forest areas were clipped out from the images using Forest Digital Map (Fig. 2).

In the next step, change detection analysis was performed using post-classification analysis and NDVI differencing methods. A layer of polygons consisting of 2 classes: forest (area covered by plants from the remote sensing point of view) and no-forest (area not covered by plants - dead plants, buildings, soil) $-50,000$ pixels each was created. Two classification methods were tested: maximum likelihood method and Mahalanobis distance Method. Each classification was verified using a similar layer of polygons. Maps of forest and no-forest areas were intersected to produce a map of changes between 2012 and 2013. They consisted of 4 classes:

- Class 0 - no-forest (no changes), an area where there were no plants in 2012 and 2013, or they were dead.

- Class 1 - no-forest - forest (+ change), an area where there were no plants in 2012, but they appeared in 2013.

- Class 2 - forest - no-forest (- change), an area where there were plants in 2012, but they were removed by 2013 .

- Class 3 - forest (no changes), an area where plants were observed both in 2012 and 2013.

The other part of the analysis was to calculate NDVI indexes for each satellite image. The values from one image were substracted from the values form the other one. The difference map was divided into 3 classes: 1,2 and 3 and 0 together. Setting the correct thresholds was crucial for the accuracy of the NDVI difference maps. The next step was to generalize the map using Focal Statistics tool in ArcGIS 10.2. It calculates the value of each pixel using mean value from the pixels in his direct neighborhood. Polygons bigger than 3 pixels $\left(75 \mathrm{~m}^{2}\right)$ were joined to the nearest polygon representing areas without changes between 2012 and 2013.

In the last part of the analysis, clouds and roads were masked using the vector layers created manually. Roads and forest paths were imported from the Forest Digital Map 2012. The buffer zone was created around them, which was 8 meters wide. It was the biggest distance between 150 parts of roads drawn manually on the 2012 and the 2013 images. Clouds, road buffers and fogs were finally clipped out from the images (Fig. 3).

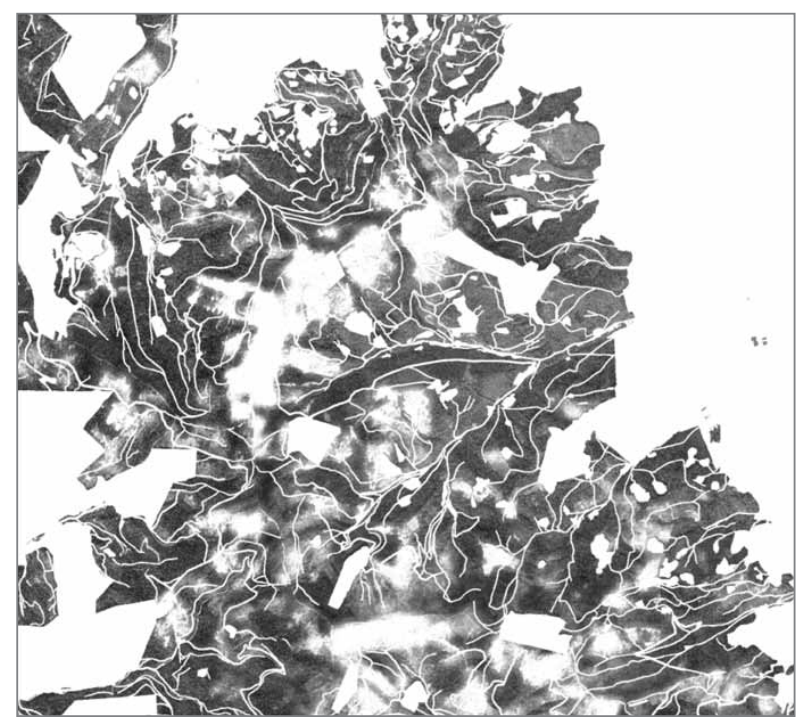

Figure 3. Masking clouds and roads

All the maps were tested using a layer of control points generated using kilometer fishnet. All the points that were lying outside the investigated area of the State Forests were removed from the layer. The reference data were the result of the visual analysis of the areas. A layer consisting of 250 points was used to estimate the overall accuracy for each map.

\section{Results}

The supervised classification performed using the maximum likelihood method and Mahalanobis distance method resulted in the production of six maps (two for each of the investigated areas) representing areas with plant coverage and areas without it. The accuracy of each map was tested using a vector layer of 100,000 pixels (50,000 for each class), similar to the one used as a classification training set. High values of the overall accuracy and Kappa obtained suggested that the supervised classification was performed well (Tab. 2).

Unfortunately, the high values of accuracy assessment and Kappa, obtained for the supervised classifications performed on separate images didn't cause the 
high values of the parameters of the final map created by intersecting them, one by another. It was verified using 250 control points. The areas of changes on the final map were relatively small according to the areas where changes were not observed. Despite the high values of accuracy assessment and Kappa of the supervised classifications, the areas of changes on the final map were not represented well enough (Tab. 3).

Table 2. The results of the supervised classification of separate images (ML - Maximum Likelihood, MD - Mahalanobis Distance)

\begin{tabular}{|c|c|c|c|c|}
\hline Results & $\begin{array}{c}\text { Accuracy } \\
\text { (ML) }\end{array}$ & $\begin{array}{c}\text { Kappa } \\
\text { (ML) }\end{array}$ & $\begin{array}{c}\text { Accuracy } \\
\text { (MD) }\end{array}$ & $\begin{array}{c}\text { Kappa } \\
\text { (MD) }\end{array}$ \\
\hline A 2012 & 98.60 & 0.97 & 98.70 & 0.97 \\
\hline A 2013 & 98.70 & 0.97 & 98.10 & 0.96 \\
\hline B 2012 & 99.60 & 0.99 & 99.40 & 0.99 \\
\hline B 2013 & 99.70 & 0.99 & 99.50 & 0.99 \\
\hline C 2012 & 98.30 & 0.97 & 99.20 & 0.98 \\
\hline C 2013 & 99.90 & 0.99 & 99.90 & 0.99 \\
\hline
\end{tabular}

Table 3. The post-classification analysis results

\begin{tabular}{|l|r|r|r|}
\hline \multicolumn{1}{|c|}{ Results } & A (\%) & B (\%) & C (\%) \\
\hline Accuracy & 76.40 & 86.00 & 78.40 \\
\hline Kappa & 0.28 & 0.61 & 0.36 \\
\hline
\end{tabular}

The second method of analysis was the NDVI index differencing method. The most crucial part of the analysis was to set the correct thresholds between the classes. The next part was to clip out roads, clouds and fogs from the map of changes. Unfortunately, it was very dif- ficult to estimate the influence of fogs on the final map. It was possible, but not before setting the thresholds; so clipping them out from the images at the beginning of the analysis was pointless. However, clipping out fogs after setting the thresholds had one disadvantage. It made setting the same thresholds on each map impossible. The map of changes contained 3 classes: 1 (noforest to forest, black), 2 (forest to no-forest, pale grey), classes 3 and 0 (areas without changes, grey) and the areas clipped out from the final map (roads, clouds and fogs, white) (Fig. 4).

The accuracy assessment of the NDVI differencing map was tested using the same layer of 250 points, which were used previously to test the post-classification map. It brought much better results than the postclassification analysis (both in the overall accuracy and Kappa) (Tab. 4).

Table 4. The NDVI differencing method results

\begin{tabular}{|l|c|c|c|}
\hline \multicolumn{1}{|c|}{ Results } & A $(\%)$ & B (\%) & C (\%) \\
\hline Accuracy & 96.50 & 97.00 & 95.20 \\
\hline Kappa & 0.86 & 0.90 & 0.86 \\
\hline
\end{tabular}

After performing post-processing, the areas of separate classes were calculated on each map. The area of "class 1" was $2.3 \mathrm{~km}^{2}$ on the area "A", $0.16 \mathrm{~km}^{2}$ on the area " $\mathrm{B}$ " and $0.49 \mathrm{~km}^{2}$ on the area " $\mathrm{C}$ ". The area of "class 2 " was $1.1 \mathrm{~km}^{2}$ on the area "A", $1 \mathrm{~km}^{2}$ on the area "B" and $2.7 \mathrm{~km}^{2}$ on the area "C".

In order to verify the changes observed on the images, a local survey within on the area of Szklarska Poręba Forest District was undertaken. 62 points were located
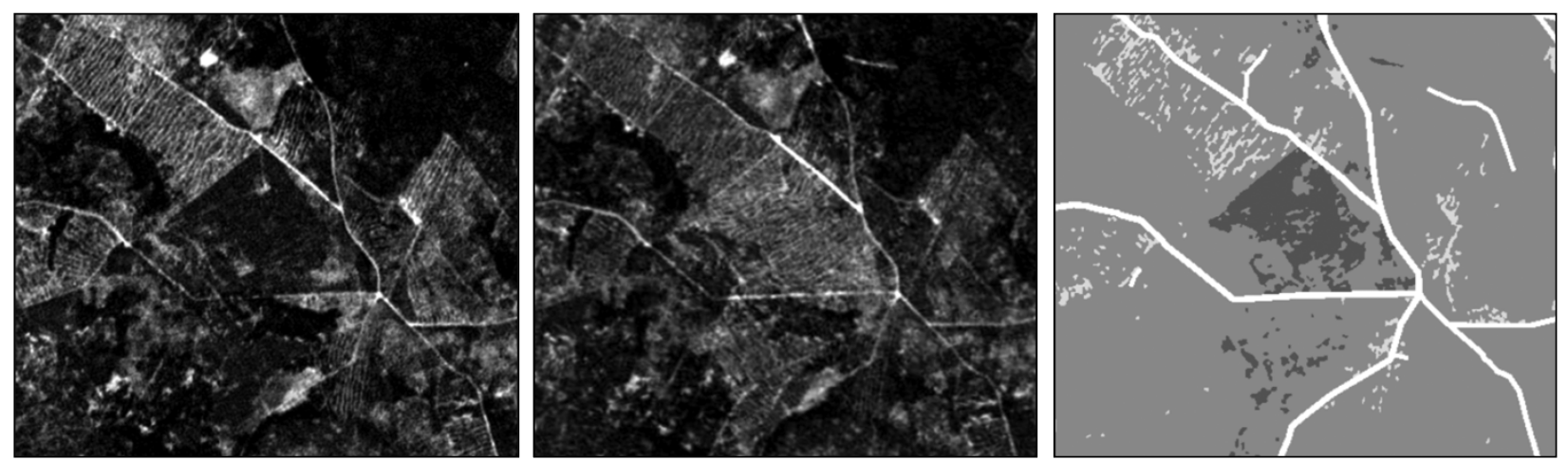

Figure 4. The NDVI differencing method results (grey - no changes, pale grey - succession, dark grey - deforestation) 
in the areas of changes on the final map and then they were verified physically with the help of the supervisor engineer or the forest ranger. 40 points represented "class 1 " areas (secondary succession) and 21 represented "class 2 " areas (deforestation). Only one point was verified incorrectly. It was a treetop that changed its location because of the river current that undermined its roots.

Among the points classified as "class 1" (no-forest to forest, change + ) there were areas of natural and artificial regeneration, which appeared as a result of planned or occasional and sanitary cuttings. Sometimes the cuttings were made earlier than 2012. However, the process of vegetative regeneration started between 2012 and 2013, so it could have been spotted on the map of changes (Fig. 5).

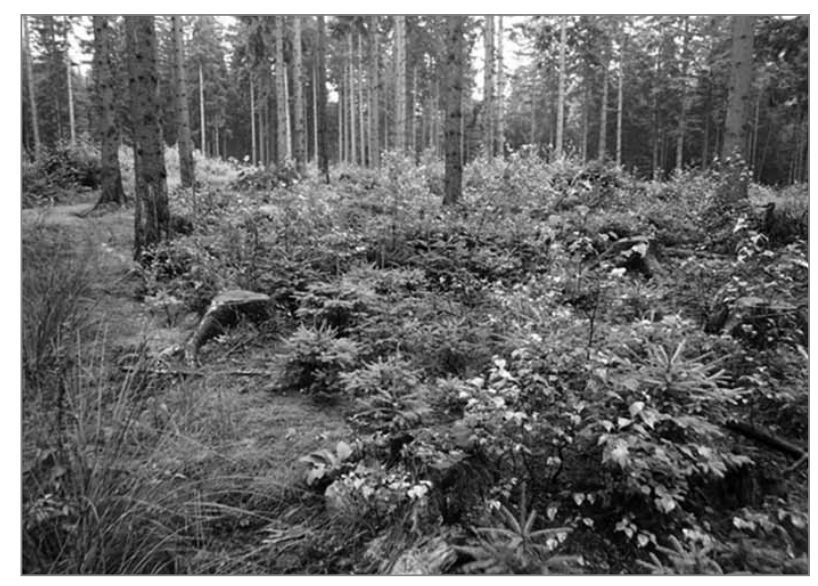

Figure 5. The example of "class 1", young spruces were uncovered by cutting

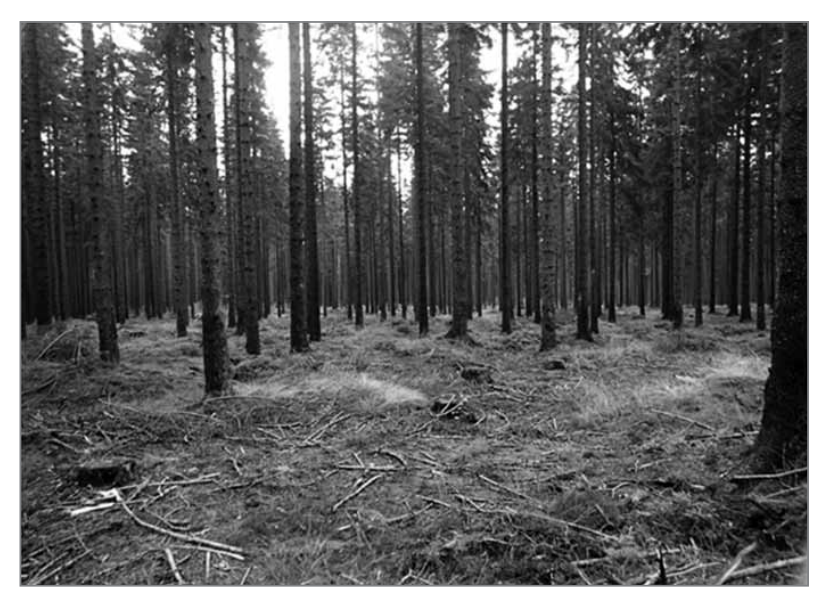

Figure 6. The example of "class 2" areas, where tree losses were identified, despite there being no large area cuttings
Among the points classified as "class 2" (forest to no-forest, - change) there were occasional, sanitary and unveiling cuttings. On the majority of the analyzed areas, there were no large (over few areas) area cuttings. It means that even cutting single trees may be visible on the map of changes. It was possible because there was often dead organic matter near the bottom of the forest performing visible changes in the spectral reflectance (Fig. 6).

\section{Discussion}

The main question that arises after performing the analysis is: "Why the high values of overall accuracy and Kappa gained for the classification of separate images did not result in high values of these factors for the change detection map created by intersecting them, one by another?" The quality of the map created by post-classification method is directly correlated with the quality of the separate classification images before intersecting. The results of the accuracy assessment were very good. So maybe, the imperfections of the Maximum Likelihood algorithm caused these mistakes? It is said that the Maximum Likelihood algorithm overestimates mixed or diversified areas. But the simple "forest, no-forest" classification cannot be treated as excessively complicated. The post-classification analysis method is said to be very effective according to many authors (Bochenek 2004; Mas 1999; Niedzielko and Lewiński 2012).

The answer to this question is dual. First of all, the boundary between forest and no-forest areas is not clear. There are no clear boundaries in the environment. Only the areas transformed by people may have clear and sharp boundaries (a gap in the old forest stands). Besides, there are many areas classified as "transitional woodlands and scrubs" in the CORINE Land Cover legend that are not easily classified as forest or no-forest. The other thing is that the areas of changes are relatively small on the images because they were made year by year. It means that even a small difference in drawing test polygons may have caused a little difference between the boundaries between forest and no-forest on the analyzed images, which was unacceptable before intersecting maps. We may say that the post-classification analysis is not a good method to perform on areas, 
where the boundaries between classes are not clear and where the area of changes is relatively small due to short time between the analyzed images.

The most effective method to detect forest-no-forest changes on such problematic areas is the NDVI differencing method. But it also has some disadvantages. Even a little misalignment between the images can result in pseudo-changes on the final map, for example, roads illustrated as two thin polygons where one represents "class 1" and the second one "class 2". To avoid these effects, the images were georectified once more using 300 georeferential points. Unfortunately, the accurate rectification, especially of the images that present high mountain areas is impossible. That is why roads were finally clipped out from the images along with buffer zone of 8 meters plus the width of the road or forest path. It was necessary to avoid detecting linear changes, which were not important in the change detection analysis.

Similar problems occurred in the case of clouds and fogs. Although the clouds might have been clipped out from the images even before the analysis, the fogs were more problematic because it was difficult to estimate the influence they had on the reflectance. It was fully possible only after setting the thresholds. Unfortunately, the fogs made it impossible to set the same thresholds on the difference images for each investigated area.

The study revealed that the accuracy of the change detection maps created for the forest districts in Sudety and Beskidy Mountains using simple NDVI differencing are comparable to the results of the studies quoted in the first chapter of the article, where some advanced methods of change detection were performed, such as: object-based classification (Elatawneh et al. 2014; Tapsall et al. 2010), mixed pixel/object-based classification (Lewiński 2007) and transformations (PCA, TC) (Arnett 2014). According to the literature, the pixel-based approach is not more or less effective than the objectbased approach when the time between the scenes is relatively short (shorter than 1 year), but we assume that the pixel-based approach could be more effective to detect subtle changes with a relatively small area than the object-based approaches - suitable for larger and more concise areas of change.

An important factor is the terminology connected with the class definitions and the specificity of the forest works. Among clear examples, where there was forest in 2012 and in 2013 it disappeared because of the cuttings, there were many exceptions and particular cases. For example, when there were living plants in the lower part of the forest, the cutting would not be observed between the images. A difference surface model would be helpful in that case. On the other hand, the areas classified as "class 1" did not represent the secondary succession of the forest, but rather the growth of grass and herbs. The conclusion is that detecting areas of the deforestation ("class 2") is far easier than detecting areas of the secondary succession ("class 1 ").

The area of investigation had also an important influence on the analysis results. The areas of highlands and mountains have their specific economy and height differences. The forest management is much more difficult to analyze there from the remote sensing point of view. Cutting have also less clear boundaries than on the lowlands. The terrain has no significant influence on processing the images. Maybe if the analysis was carried out in the lowlands, on the areas where Scots pine forests are more common, the results and conclusions would be different and probably easier to automate.

A complementary survey should focus on the ability to use the results of the analysis in local forestry. The update of the Digital Forest Map takes place once a year in December or in January. The images, used in the analysis, must be taken during the vegetation period (June-September). Therefore, the annual comparison between the Forest Digital Map and the results of change detection analysis based on satellite imagery is incoherent.

\section{Conclusions}

The high values of overall accuracy and Kappa (over 95\%) of the separate Black-Bridge image classifications, the areas of changes were not represented well on the final map produced as a result of post-classification analysis. The NDVI differencing method is more effective to detect forest - no-forest changes especially on areas where the boundaries between classes are unclear and when the areas of changes are relatively small. The fogs are very problematic for the analysis because they change the values of reflectance, but it is hard to estimate the influence before setting the thresholds. The practical usage of the analysis based on remote sensing 
data to update the Digital Forest Map still depends on the agreement between its results and the data collected in the State Forests Information System database.

\section{References}

Adelabua S., Mutangaa O., Adamb E. 2014. Evaluating the impact of red-edge band from Rapid-eye image for classifying insect defoliation levels. Journal of Photogrammetry and Remote Sensing, 95, 34-41.

Arnett J.T.T.R. 2014. Using RapidEye satellite imagery to detect forest disturbances in British Columbia. M. Sc. thesis, University of British Columbia.

Bałazy R. 2002. Analiza klęski ekologicznej w Sudetach Zachodnich na przykładzie Nadleśnictwa Szklarska Poręba. M. Sc. thesis, The Environmental University in Poznań.

Bochenek Z. 2004. Opracowanie metodyki określania zmian użytkowania ziemi na podstawie cyfrowej analizy wysokorozdzielczych zdjęć satelitarnych. The Works of Geodesy and Cartography Institute, 106, 27-61.

Campbell J.B., Wynne R.H. 2011. Introduction to remote sensing. The Guilford Publications.

Elatawneh A., Rappl A., Schneider T., Knoke T. 2012. A semi-automated method of forest cover losses detection using RapidEye images: a case study in the Bavarian forest National Park. In: RapidEye Science Archive (RESA) - Vom Algorithmus zum Produkt (eds.: E. Borg, H. Deadelow, R. Johnson). GITO Verlag, 183-200.

Elatawneh A., Wallner A., Manakos I., Schneider T., Knoke T. 2014. Forest cover database updates using multi-seasonal RapidEye data - storm event assessment in the Bavarian Forest National Park. Forests, $5,1284-1303$.

Kozak J. 2003. Forest cover change in the Western Carpathians in the past 180 years. Mountain Research and Development, 2 (4), 369-375.

Lewiński S. 2007. Porównanie klasyfikacji obiektowej $\mathrm{z}$ tradycyjną klasyfikacją pikselową z punktu widzenia automatyzacji procesu tworzenia bazy danych o pokryciu i użytkowaniu terenu. The Volumes of Geomatics, 5 (1), 63-70.
Lillesand T.M., Kiefer R.W., Chipman J.W. 2007. Remote sensing and image interpretation. John Wiley and Sons.

Lu D., Mausel P., Brodizio E., Moran E. 2004. Change detection techniques.

International Journal of Remote Sensing, 25 (12), 2365-2401.

Mas J.F. 1999. Monitoring land-cover changes: a comparison of change detection techniques. Remote Sensing, 20 (1), 139-152.

Niedzielko J., Lewiński S. 2012. Detekcja zmian pokrycia terenu na zdjęciach satelitarnych Landsat - porównanie trzech metod. Teledetekcja Środowiska, 47, 87-98.

Potocki J. 2000. Przemiany użytkowania terenu w Karkonoszach w ciągu ostatnich 100 lat (podłoże społeczno-ekonomiczne, środowiskowe konsekwencje). Opera Carcontica, 37, 642-649.

Rodriguez A.C., Noel J.A., Hansen M.C. 2014. Forest cover change: using Rapid Eye data to validate the accuracy of landsat data in Brazil. University of Maryland.

Stereńczak K. 2006a. Aktualizacja leśnej mapy numerycznej na przykładzie wybranych obiektów Nadleśnictwa Rogów. M. Sc. thesis, Warsaw University of Life Sciences.

Stereńczak K. 2006b. Aktualizacja Leśnej Mapy Numerycznej w opiniach jej użytkowników. The Volumes of Geomatics, 4 (4), 185-192.

Szymura T.H., Dunajski A., Ruczakowska A.M. 2010. Zmiany powierzchni lasów na obszarze Karkonoskiego Parku Narodowego w okresie 1747-1977. Opera Carcontica, 47 (1), 159-166.

Tapsall B., Milenov P., Taşdemir K. 2010. Analysis of Rapid-eye imagery for annual landcover mapping as an aid to European Union (EU) Common Agricultural Policy. In: Proceedings of ISPRS TC VII Symposium - 100 Years ISPRS / IARPS (eds.: W. Wagner, B. Szekely), July 5-7, 2010, Vienna, Austria.

Wężyk P., Ciechanowski P. 2005. Wykorzystanie wysokorozdzielczych zobrazowań satelitarnych Quickbird-2 w aktualizacji baz danych Leśnej Mapy Numerycznej. The Volumes of Geomatics, 3 (4), 199-208. 